\title{
Cleaning of Solar Panel using Automation Technique
}

\author{
A.Sairaj ${ }^{1}$ and Dr. K. Shashidhar Reddy ${ }^{2}$ \\ ${ }^{1}$ PG Scholar, CVR College of Engineering/ EEE Department, Hyderabad, India \\ Email: sairajelectricalengineer123@gmail.com \\ ${ }^{2}$ Professor, CVR College of Engineering / EEE Dept.,Hyderabad, India \\ Email: shashidhar.kotha5@gmail.com
}

\begin{abstract}
Solar energy is considered to be one of the best major renewable energy resources to generate and meet the electrical energy demand of the entire globe. Solar PV modules produce electricity by collecting the sunlight. solar PV modules are generally employed in dusty environmental areas like in India, which comes under the tropical region. Various dust particles present in the tropical region, so the dust particles are accumulated on the surface of the solar panel. Therefore, the incident light can be blocked. As a result, the module power capacity can be reduced. If the panel not cleaned properly the power output become reduced by $50 \%$. To increase the power output an automatic cleaning mechanism has been designed. This automatic cleaning mechanism not only senses the dust accumulated on the solar panel but also clean the solar PV module automatically. This solar cleaning mechanism is mainly implemented using PIC 16F 1527 microcontroller, which mainly controls the stepper motor, Air compressor and water pump. The dust can be cleaned by the gantry which is mainly driven by the stepper motor. The gantry has mist nozzles which create pressurized air and water to clean the solar panel effectively. The cleaning can be done by air and water depending upon the dust accumulated on the solar panel.
\end{abstract}

Index Terms: solar panel; micro-controller; stepper motor; dust particles.

\section{INTRODUCTION}

The Solar panel cleaning mechanism is one of the best methods to clean the accumulated dust on the solar panel. Renewable energy resources have a major contribution to distributed generation. Solar energy plays a vital role in producing the distributed generation. Solar panels are used as the main power source for most the applications like agriculture, industrial as well as domestic applications. There are many types of solar panels. Dust build-up on solar module surface is an issue of great worry, particularly in desert provinces regular dust storms occur. The glass cover transmittance decreases because of the accretion of dust on the surface of the PV module, which ultimately decreases the amount of solar irradiation reaching the cells [1].

The dust density of the surface, orientation, the tilt angle, exposure period, dominant wind direction, and site climatic conditions are the main key factors to reduce the glass transmittance. The dusty environment countries produce a lot of dust on the solar panel as a result the transmittance of solar energy reduces on the solar panel. India faces this kind of problem. The accumulated dust decreases the tilt angle as a result sufficient amount of solar energy is not produced; the best way to eliminate the accumulated dust on the environment is to clean the solar panel.
In some places, the cleaning process is very complex for humans. This complexity can be reduced after the invention of an automation cleaning mechanism like an autonomous robot (Gantry). Gantry cleaning is the most effective way of cleaning in recent years. Gantry cleaner is an autonomous device that can move around and clean the surface using different techniques such as air and water jet cleaning. The proposed solar panel cleaning system falls in the category of cleaning gantry mechanism, but for industrial cleaning application in large scale solar power plants [2]. Dust may be defined as crushed form which is in the form of hundreds of microns. Dust may come in the environment from various sources such as construction sites, industries and other dust produced areas. Dust consists of floating invisible, visible and fallen particles of solid material. The authors have compared the various dust particles present on the solar panels, which mainly degrade the efficiency of solar panel. They also reported that a small amount of dust on the solar PV module creates a blockage for solar incident rays. Researchers conducted studies on the effect of different influential parameters on the efficiency and performance of PV cells [3]. Solar panels can be cleaned by two ways, they are:

1. Manual cleaning

2. Automatic cleaning using gantry

\section{Manual Cleaning:}

This type of cleaning is tedious, cumbersome and also expensive in terms of the labor involved and time. It requires more manual setup and time consumption. To clean the solar panel manually has the following disadvantages [3].

\subsection{Non-Uniform Pressure During The Cleaning:}

Manually, the pressure exerting on the solar panel is not always equal. With too high pressure the panels can be damaged in the worst case. If the pressure on the other hand is too low, the surface will not be thoroughly cleaned.

\subsection{It Is Not Possible To Manually Clean The Whole Solar Panel Surface:}

Solar panels constructed at a certain height have corners and sides that are difficult to reach. It is very difficult even if we use scrubber.

\subsection{People Become Tired And Made Mistakes:}

The solar PV panels occupy more surface areas so cleaning the total solar panels with manual set up require more time [3]. The following are the common human errors:

- Panel surface areas are not cleaned properly. 
- A wrong or sudden movement can cause scratches.

\subsection{Manual Cleaning Solar Panels Are Not Always Safe.} panels.

There are two important aspects to clean the solar

\section{- Safety of PV Installation:}

As mentioned above, manual cleaning entails a potential risk. Your valuable installation can be accidently damaged by human error [4].

\section{- Safety of Cleaning Team.}

Cleaning staff often work in dangerous circumstances during cleaning of the solar panel. There is particularly a risk of accidents when the panels are installed at a certain height [2].

Because of above disadvantages the manual cleaning of solar panel is time consuming and laborious. In order to overcome the above disadvantages, we prefer the automation cleaning [5].

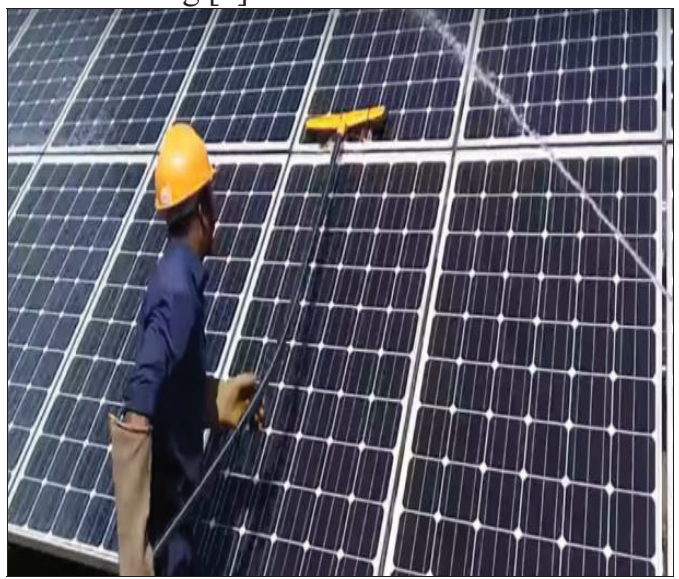

Figure1. Manual cleaning.

\section{Automatic Cleaning Using Gantry:}

This is the most innovative way of cleaning solar panels with the help of a microcontroller. This type of cleaning is very advantageous over manual cleaning since it doesn't require labour. It consumes very little time to clean the solar panels [6].

The following are the desired functions of an automated solar panel cleaning system: To cover cleaning area of solar panel in minimum amount of time.

- To cover the cleaning area of solar panel in a minimum amount of time.

- To use a high-velocity water jet for cleaning.

- To automate the water jet gantry movement in forward and reverse directions.

- To control the speed of movement of the gantry.

- To automatically detect the edges of the panels and stop the gantry movement.

- To automatically switch on or switch off the gantry, air compressor and water pump.

- To control the cleaning cycle as per the given schedule.

- To estimate the dust using water and air-jet cleaning equipment.

- To estimate the overall cost for cleaning the $1 \mathrm{MW}$ capacity of panels based on this component
- To implement control algorithm on an embedded controller.

- To identify and select the high-velocity jet nozzles.

- To size the water pump suitable for the nozzles.

- To understand air jet cleaning in place of water jet cleaning.

- To identify air jet nozzles suitable for dusting.

- We can easily analyze the mechanical design of the supporting structure.

- We can easily clean the edges and corners of the entire solar panel.

Automatic cleaning is an accurate cleaning and improves the efficiency of the solar panel and reduces the consumption of water [7].

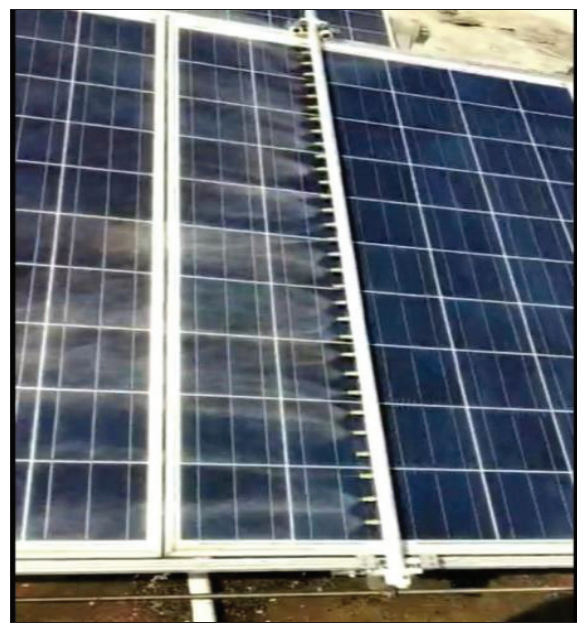

Figure 2. Automation cleaning.

\section{Proposed Method}

Initially provide power supply to the control panel which has the control components of the entire cleaning mechanism. In the control panel, we have a control circuit, protection relays, contactors and optocoupler. After Switch on the control panel, the converted power through SMPS enter into the CPU board. The CPU board consists of control and conversion components.

The control panel can be operated either manually or automatically.

\subsection{Manual Mode:}

- First switch on the air compressor and fill the compressor with air up to its maximum level.

- Now press the push buttons to run the gantry in a forward direction.

- The gantry can be driven with the help of a stepper motor, i.e., the gantry moves in both forward and backward direction by a stepper motor.

- Now activate solenoid valve 1 , so the compressed air comes through the nozzles and cleans the accumulated dust on the solar panel. The Air jet cleaning process is during the forward direction of the gantry.

- When the gantry reached to the desired length, the gantry can be stopped with the help of home switch. 
- Now press the push button to run the gantry in a backward direction, after that press the water pump push button.

- Now activate solenoid valve2. The water comes through the gantry and cleans the panel in the backward direction.

- After reaching the gantry at the starting point, now stop the operation by using a push-button.

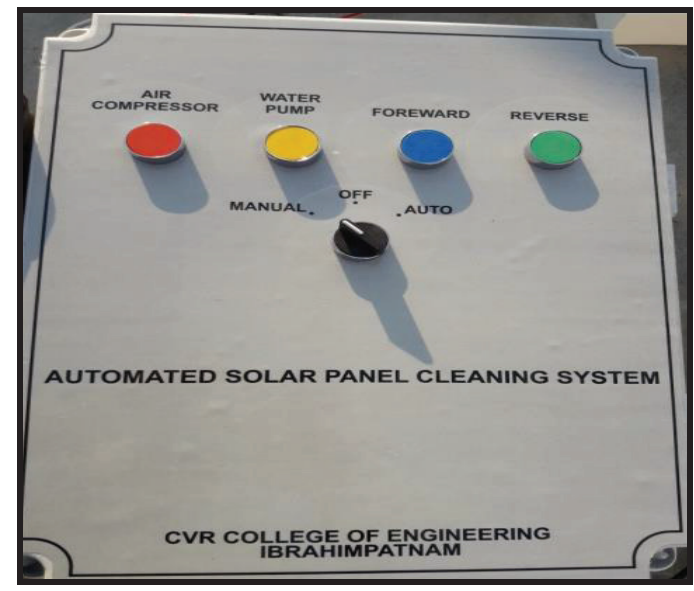

Figure3. solar panel cleaning system in manual mode.

\subsection{Automatic Mode:}

- The total operation can be controlled by a microcontroller (PIC 16F 1527). Now embedded the time to fill the air compressor and dump this value into the microcontroller.

- Now embedded the stepper motor control and gantry movement i.e., both forward and reverse direction phenomenon code can be dump into the microcontroller.

- Now embedded the solenoid valves operation code and the water pump switch on timing can be dump into the microcontroller.

- Embedded the time taken to reach the gantry at the desired length and maintain the delay operation can be dump into the microcontroller.

- Fix the time delay of $2-3$ seconds for each operation and dump this time delay microcontroller.

Both these modules can be operated manually as well as Automatic mode depending upon the type of conditions present at the plant location. The only difference in manual mode is, it requires manual support but Automatic mode does not require any manual support it Automatically cleans the solar panel, depending upon its time grading. The time interval fixed in a microcontroller, i.e., the time interval of gantry movement can be fixed in a microcontroller depending upon the weather condition.

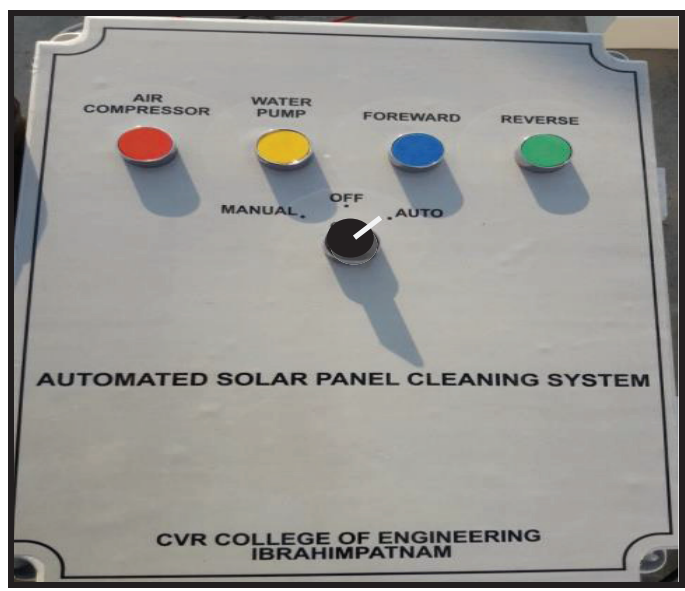

Figure4. solar panel cleaning system in Auto mode.

\section{BLOCK DIAGRAM}

Figure3. Describes the block diagram of Aautomatic solar panel cleaner. It has various stages of operation.

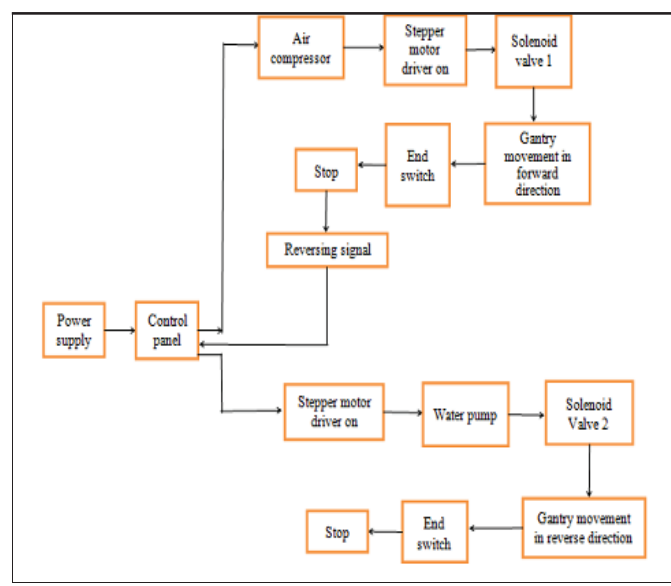

Figure 5. Block diagram of Automatic solar panel cleaner.

IV. FLOW CHART

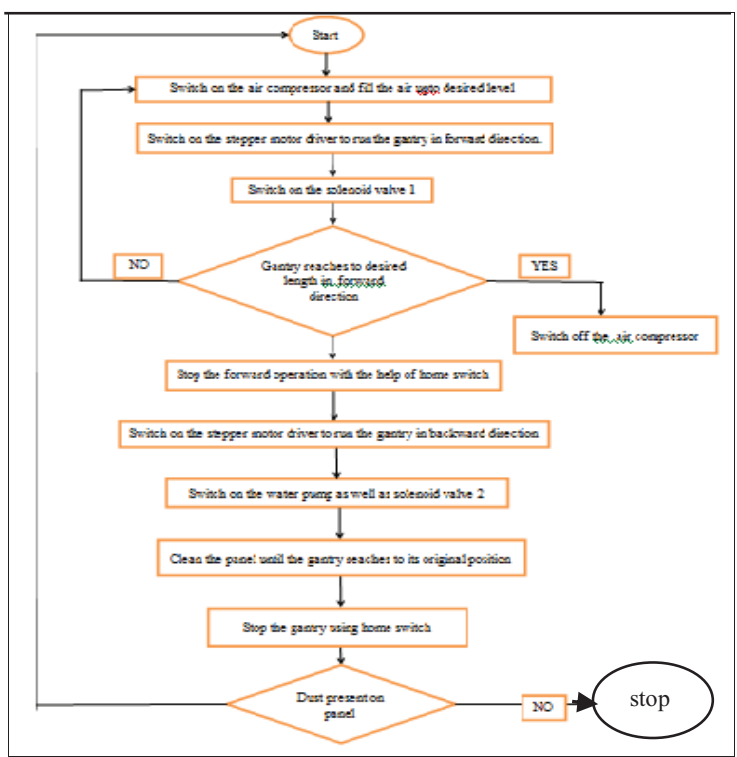

Figure 6. Flow chart of automatic solar panel cleaner. 


\section{Control Panel}

Control panel mainly has the following components.

5.1. Main circuit

5.2. Stepper motor driver

5.3. Optocouplers

5.4. Relays and contactors

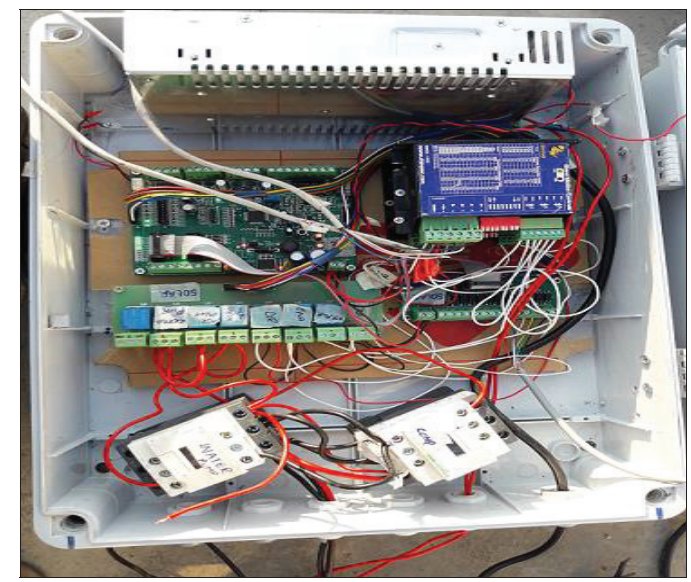

Figure 7. Control panel

\subsection{Main Circuit (Central Processing Unit):}

Main circuit has the following components.

5.1.1. Micro controller (PIC 16 F 1527)

5.1.2. Switched mode power supply (SMPS)

5.1.3. Switching regulator

5.1.4. Capacitors, resistors

5.1.5. Male and female sockets

\subsubsection{Microcontroller (PIC 16F 1527):}

It is the main component of main circuit, all the user defined operations are programmed and they were embedded in this microcontroller. In automation of solar panel cleaner PIC 16F 1527 micro controller is used.

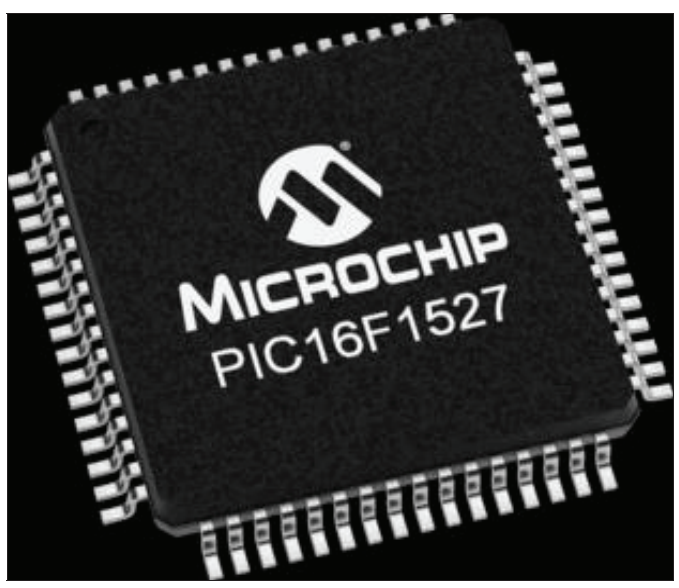

Figure 8. Micro controller PIC 16F 1527.
- Up to 28 Kbytes Linear Program Memory Addressing.

- Up to 1536 Bytes Linear Data Memory Addressing.

- It has I/O Ports, Primary and data memory, and EEPROM, UART, PWM Operation and I2C operation.

- Operating Speed:

- DC - $20 \mathrm{MHz}$ clock input at 2.5V

- DC $-16 \mathrm{MHz}$ clock input at $1.8 \mathrm{~V}$

- DC - 200 ns instruction cycle

The PIC 16F 1527 micro controller consist of the following inherent features:

- It has input and output ports

- Primary and data memory

- EEPROM

- UART

- PWM OPERATION

- $\mathrm{I}^{2} \mathrm{C}$ operation

\subsubsection{Switched Mode Power Supply (SMPS):}

Initially we provide supply to the control panel; control panel gets on with the help of SMPS. Which converts the voltage from $230 \mathrm{~V}$ (AC) to $24 \mathrm{~V}$ (DC). In this control panel we used (Mean well LRS-50-24) SMPS. It has the following features:

- No load power consumption.

- High operating temperature up to $700 \mathrm{C}$.

- LED indicator for power on

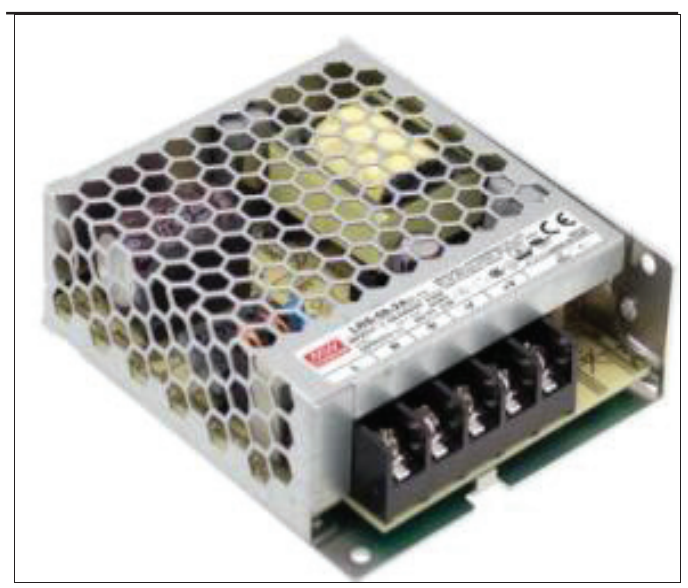

Figure.9. SMPS

\subsubsection{Switching Regulator:}

Switching regulator is used to convert the voltage from any dc voltage to desired optimal voltage, which is in the order of $5 \mathrm{~V}, 10 \mathrm{~V}$ etc. In control panel I have used LM $2576 \mathrm{~T}$ switching regulator.

The PIC 16F 1527 micro controller has the following features:

- Only 49 Instructions 


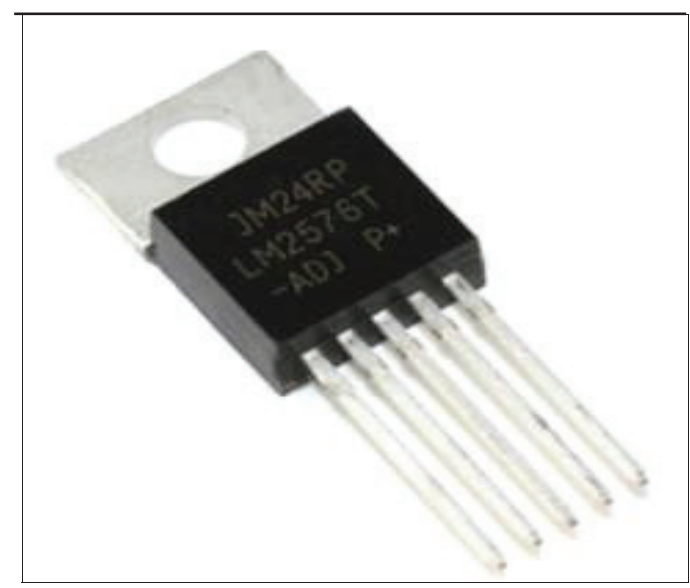

Figure 10. Switching regulator.

\subsubsection{Capacitors \& Resistors:}

These are mainly used in control panel to control higher voltage and currents. Especially capacitors mainly used as a filters, which removes the unwanted ripples in a dc output.

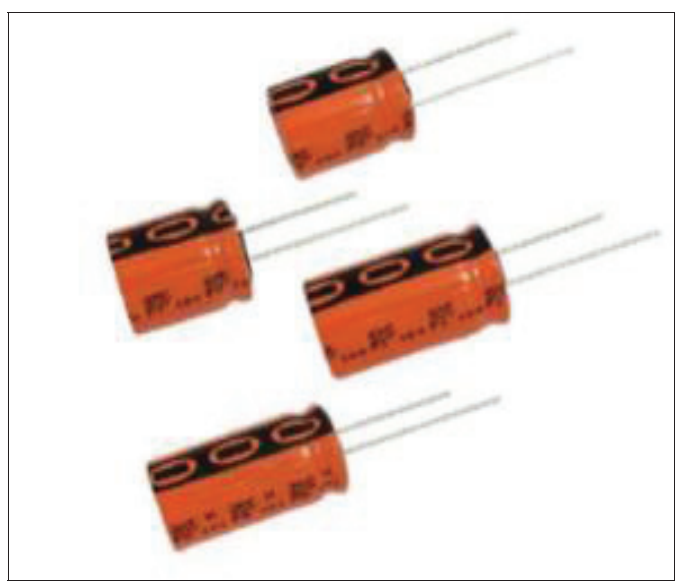

Figure 11. Capacitors

\subsubsection{Male \& Female Sockets:}

Male and female sockets act as interface between one terminal and other terminal in control panel.

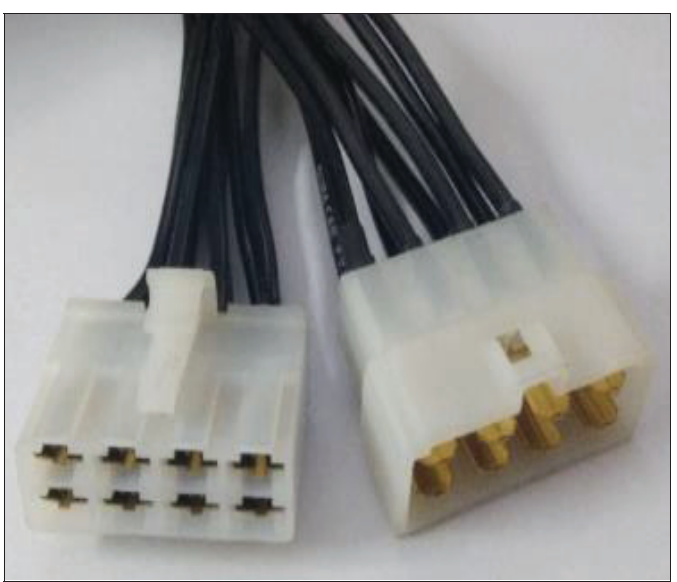

Figure 12. Male and female sockets

\subsection{Stepper Motor Driver:}

Stepper motor is an electromechanical device which converts electrical pulses into discrete mechanical movements. Depending upon the step angle through which motor shaft rotates for each command pulse of input.

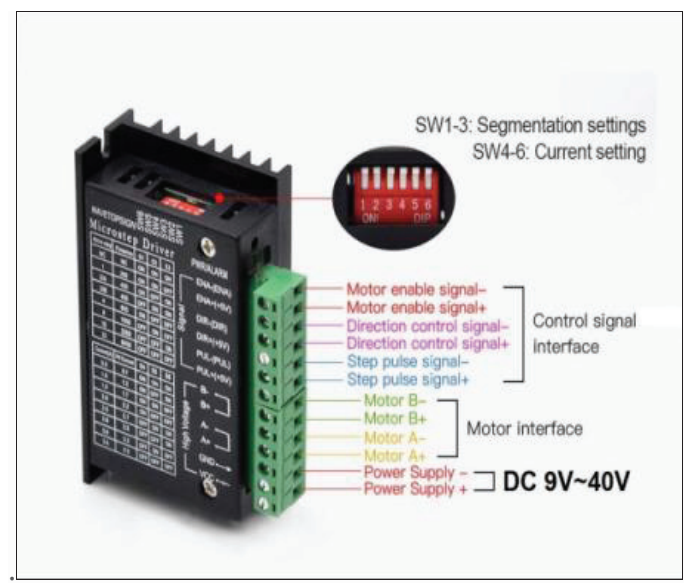

Figure 13. Stepper motor driver.

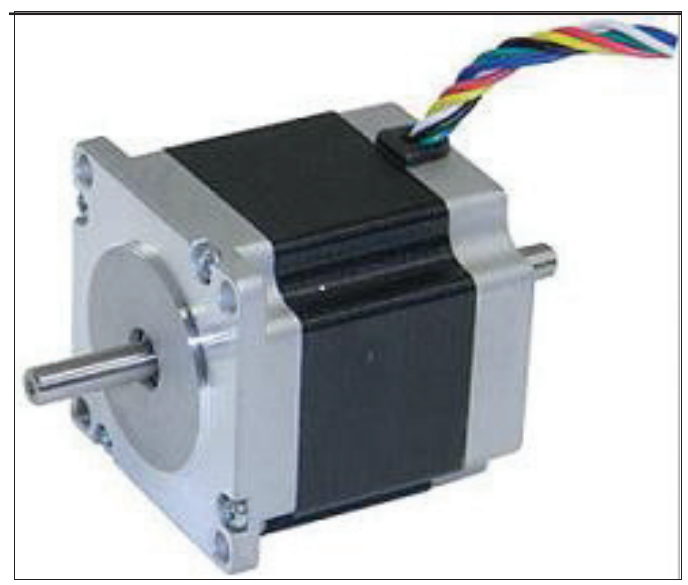

Figure 14. Stepper motor (NEMA 23).

\subsection{Optocoupler:}

Optocoupler is mainly used to isolate electrical connections in the form of light energy. In control panel we used the PC817 optocoupler. A basic optocoupler is shown below. 


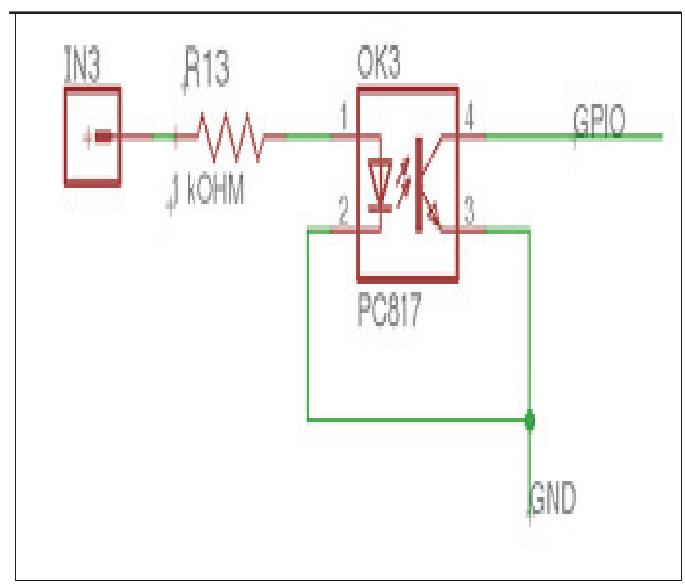

Figure 15. Optocoupler PC 817 connections.

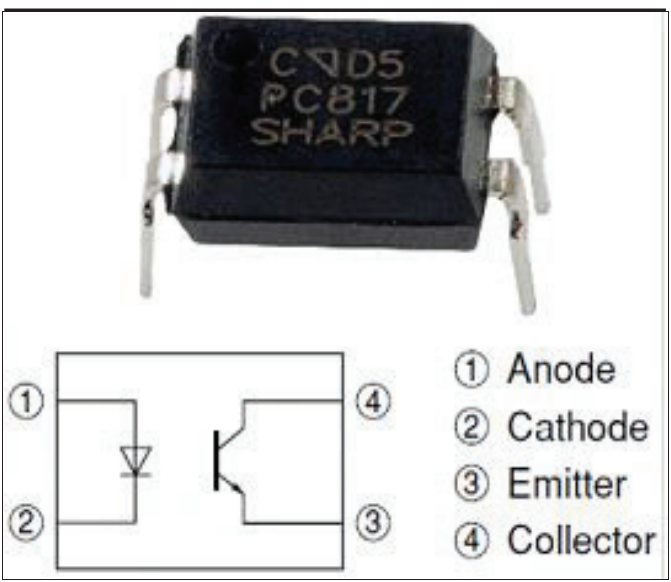

Figure 16. Optocoupler PC 187.

\subsection{Relays \& Contactors}

This section describes the relays, contactors, which mainly operate the air compressor and water pump.

\subsubsection{SPDT Relays.}

The electromagnetic SPDT relays (JQ 3F-C-S-10-DC $24 \mathrm{~V}$ ) are used in automatic solar panel cleaner. The rating of this relay is

- Coil voltage: $24 \mathrm{~V}$ DC

- Current: 10A, Coil power: $0.45 \mathrm{~W}$

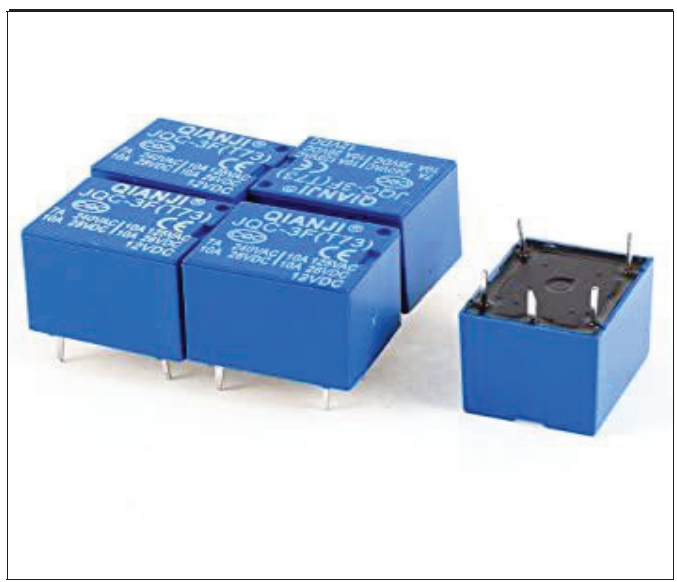

Figure 17. SPDT Relay.

\subsubsection{Contactors:}

The power-controlled contactors (LC 1E 12) are used in automatic solar panel cleaner. The rating of contactors are as follows:

Minimum Switching Current:

- $5 \mathrm{~mA}$ for signalling circuit.

- Minimum Switching Voltage: $17 \mathrm{~V}$ for signalling circuit

- Non-Overlap Time: $1.5 \mathrm{~ms}$ on energisation between NC and $\mathrm{NO}$ contact, $1.5 \mathrm{~ms}$ on de-energisation between $\mathrm{NC}$ and NO contact

- Insulation Resistance: $>10 \mathrm{M} \Omega$ for signalling circuit.

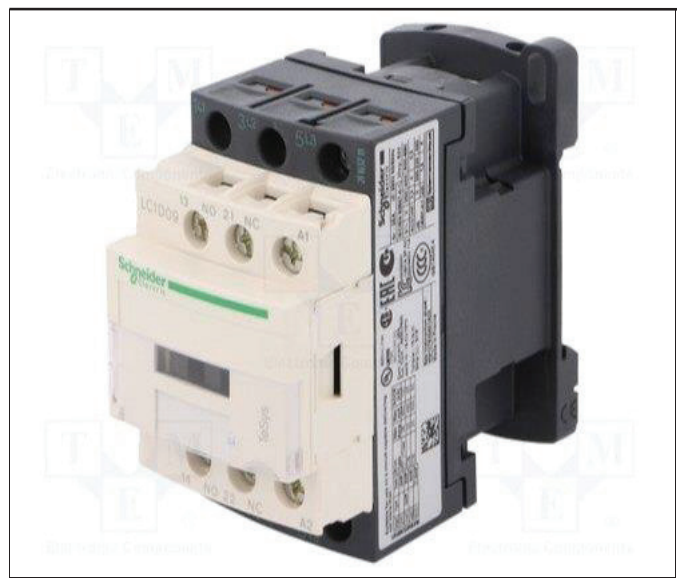

Figure 18. Contactors.

Relay and contactors are mainly used to operate the Air compressor and water pump. Whenever abnormal conditions will occur in the circuit then the contactor isolates the air compressor and water pump connections.

\subsubsection{Water Pump:}

This water pump is mainly used to clean the solar panel to create optimum amount of pressure to remove dust on solar panel through water.

- Horse Power: 1H.P

- Max Current: 5A

- Rotational Speed: 2800rpm

- Head: $25 \mathrm{~m}$

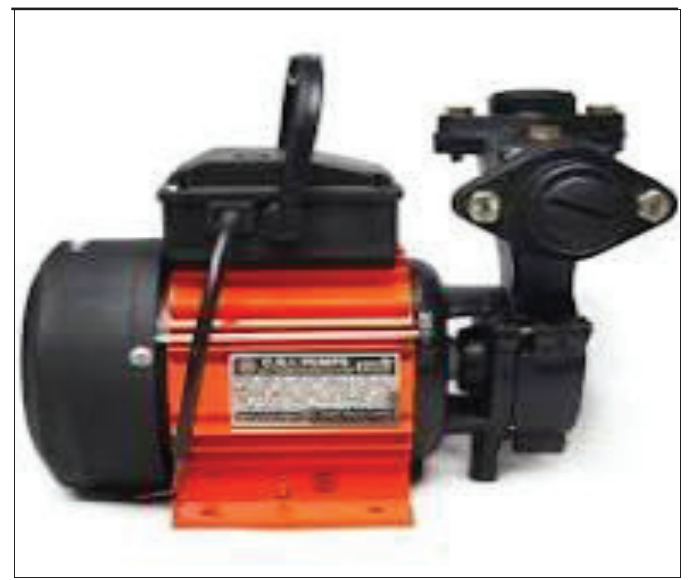

Figure 19. Water pump. 


\subsubsection{Air Compressor:}

Air compressor is mainly used to clean the solar panel to create optimum amount of pressure to remove dust on solar panel through air.

- Max. pressure: 8 bar

- Tank volume: 24 Liter

- Air displacement:161 liter/min

- Horse power: $1.5 \mathrm{hp}$

- Powerful pump, less than 2 minutes to fill the tank to maximum pressure.

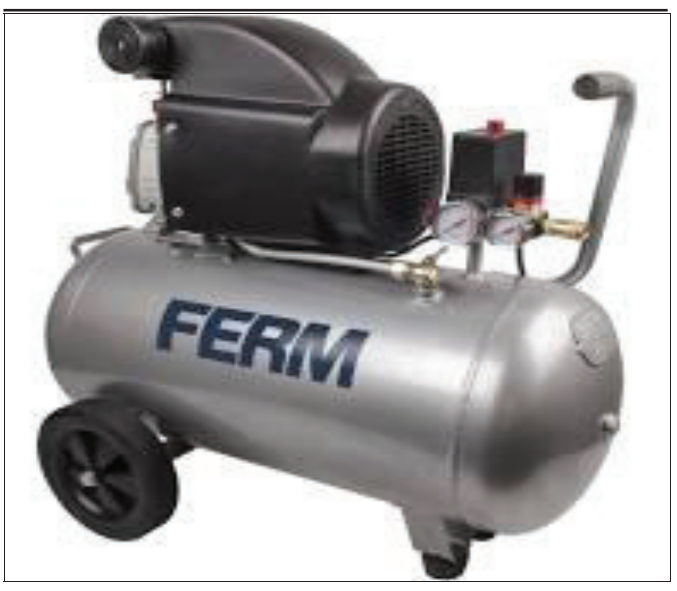

Figure 20. Air compressor

Not only these components used in solar panel cleaner, but also used the following components they are:

v. Solenoid valve

vi. Nozzles

vii. Aluminium pipe

viii. Screw rod

ix. Aluminium extrusion

x. Guide bars

\subsubsection{Solenoid Valve:}

Solenoid valves are control units, which are electrically energized or de energized. Whenever we provide electrical supply to the solenoid, the valve will automatically open and provides path for water as well as air flow.

In solar panel cleaner two solenoid valves are present, one is for air and one is for water.

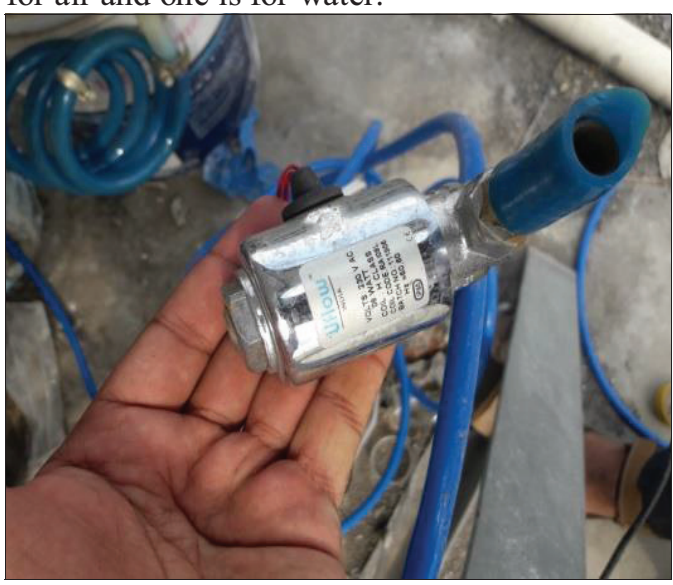

Figure 21. Solenoid valve

\subsubsection{Nozzles:}

In solar panel cleaner the Nozzles play vital role to conserve water,and the air flow can be very high.i.e. It creates high pressure, which is main advantageous to clean the solar panel.

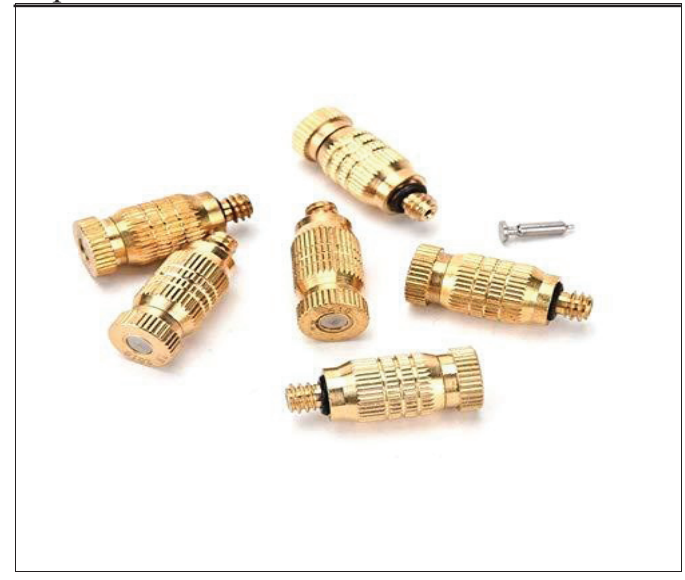

Figure 22.Mist Nozzles

\subsubsection{Aluminium Pipe:}

- An $25.4 \mathrm{~mm}$ OD Aluminum pipe with $3 \mathrm{~mm}$ thickness has been used to attach nozzles.

- The pipe has been drilled at regular intervals along the length.

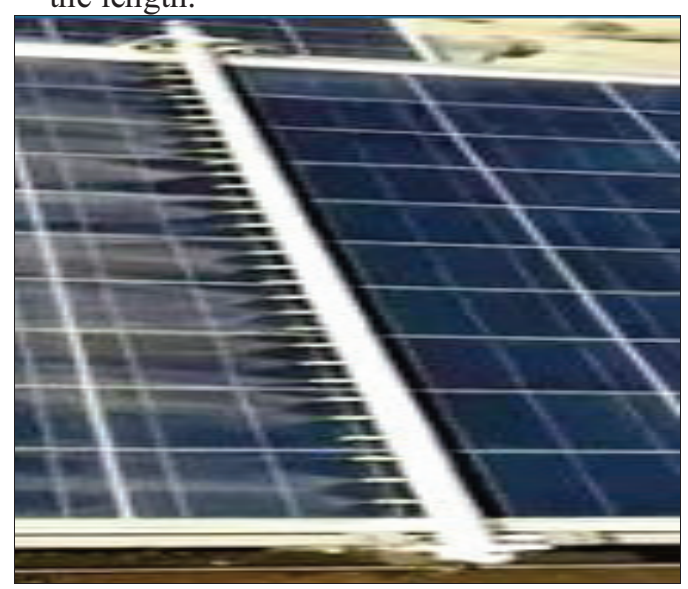

Figure 23.Aluminium pipe.

\subsubsection{Screw Rod:}

M12 ISO Metric threaded screw rod suspended at both ends on ball bearings and coupled to stepper motor has been used to move gantry along the solar panels

- Pitch: $1.6 \mathrm{~mm}$

- Diameter: $12 \mathrm{~mm}$

- Length: $2000 \mathrm{~mm}$ 


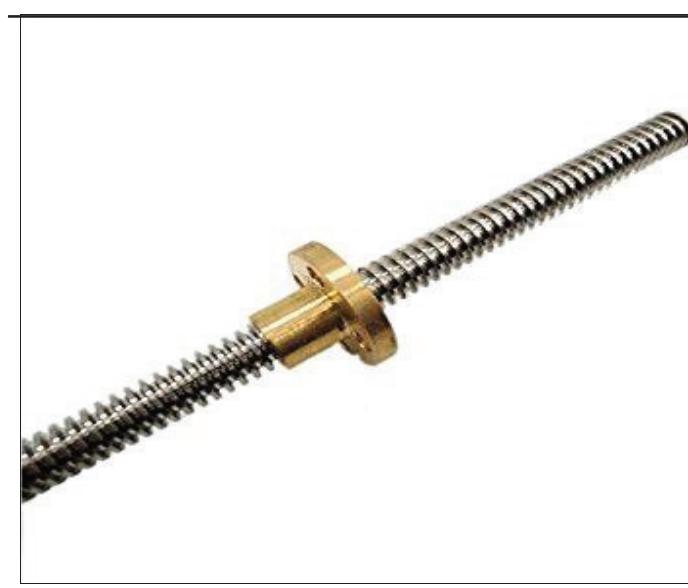

Figure 24.Screw rod.

\subsubsection{Aluminium Extrusion:}

Aluminium extrusion is mainly used to guide the wheels to move forward as well as reverse direction.It provides free movement to the guide bars.

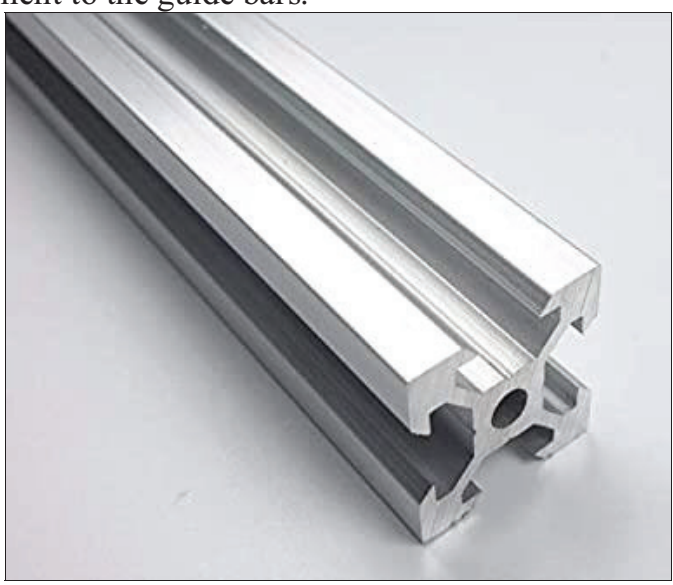

Figure 25. Aluminium extrusion.

\subsubsection{Guide bars:}

20X40 Aluminum extrusion along with delrin wheels has been used as guide bars for the gantry.

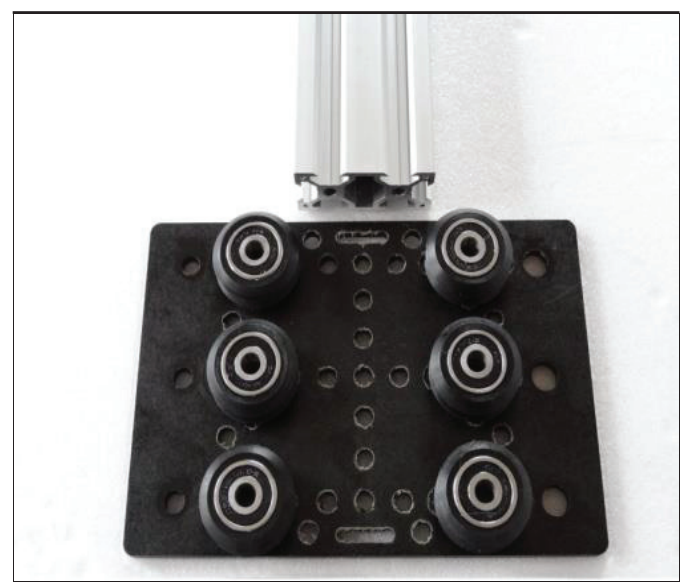

Figure 26. Guide bars.

\section{Final Results}

With the help of solar panel, the following results are observed:

- The optimum amount of water can be utilised by this solar panel cleaner. Manually it takes 25 litres of water to clean two solar panels. With the help of solar panel cleaner, it takes around 0.5-1 litres of water.

- The solar panel can be cleaned at any time as per our requirement. Generally, regular interval of time is preferable, depending upon the dust accumulation on the solar panel.

- The efficiency of solar panel increased effectively. TABLE I.

P-V VALUES When Dust ACCUMULATION ON SOLAR PANEL

\begin{tabular}{|c|c|c|c|}
\hline DATE & DAY & VOLTAGE (V) & POWER (W) \\
\hline 01-02-2020 & I & 32 & 125 \\
\hline 02-02-2020 & II & 29 & 119 \\
\hline 03-02-2020 & III & 24 & 104 \\
\hline 04-02-2020 & IV & 21 & 99 \\
\hline 05-02-2020 & V & 20 & 85 \\
\hline 06-02-2020 & VI & 22 & 70 \\
\hline $07-02-2020$ & VII & 21 & 60 \\
\hline & \multicolumn{2}{|c|}{ AVERAGE POWER(W) } & 94.57 \\
\hline
\end{tabular}

TABLE II.

P-V Values After Cleaning the Solar Panel.

\begin{tabular}{|r|c|c|c|}
\hline DATE & DAY & VOLTAGE (V) & POWER (W) \\
\hline $01-02-2020$ & I & 40 & 155 \\
\hline $02-02-2020$ & II & 39 & 152 \\
\hline $03-02-2020$ & III & 36 & 150 \\
\hline $04-02-2020$ & IV & 35 & 149 \\
\hline $05-02-2020$ & V & 37 & 150 \\
\hline $06-02-2020$ & VI & 38 & 151 \\
\hline $07-02-2020$ & VII & 39 & 150 \\
\hline & \multicolumn{2}{|c|}{ AVERAGE POWER(W) } & 151 \\
\hline
\end{tabular}

By considering the above results the following observations were obtained:

The power and voltage values gradually decrease because of the dust accumulated on the solar panel, where the values are considered for one solar panel under offload condition.

- From table I. (PV values when dust accumulated on the solar panel), depicts that the voltage and power levels are reduced. As a result, the efficiency of the solar panel reduces.

- From table II. (PV values when the dust cleared by solar panel cleaner), observed that the power and voltage values are slightly reduced when compared to table I. Reduction is due to the uneven dust deposition from the day I - day VII, i.e., the dust cannot be predicted exactly the day by day. The efficiency of the solar panel increased when the dust was cleared on the solar panel. 
The performance of solar panel can be improved effectively by using the solar panel cleaning. The efficiency can be calculated as follows:

$$
\text { Efficiency }(\eta)=\frac{\text { Amount of power }(\mathrm{w}) \text { obtained }}{\text { power rating of the solar panel }}
$$

The efficiency of solar panel can be degraded as follows:

- The weather condition plays very important role in the solar panel efficiency such as sun intensity, humidity, and huge amount of heat dissipation.

- Dust particles and bird drops also one of the major reasons to degrade the efficiency.

- Low quality material is used in the solar P-V cells also caused to reduce the efficiency of solar panel.

Efficiency comparison between the solar panels using automation and without using automation is as follows:

Efficiency of solar panel without using Automation:

$$
\text { Efficiency }(\eta)=\frac{\text { Average power obtained in }(W)}{\text { power rating of the solar panel }}
$$

$$
\begin{aligned}
& \eta=\frac{94.57}{500} * 100 \\
& \eta=18.91 \%
\end{aligned}
$$

Note: Average power considered from TABLE I.

$>$ Efficiency of solar panel using Automation:

Efficiency $(\eta)=\frac{\text { Average power obtained in }(\mathrm{W})}{\text { power rating of the solar panel }}$

$$
\begin{aligned}
& \Pi=\frac{151}{500} * 100 \\
& \eta=30.20 \%
\end{aligned}
$$

Note: Average power considered from TABLE II.

Initially, the power and voltage can be in optimum value in both cases, i.e., the solar panel is using with automation and without automation. Whenever the dust accumulated on the surface of the solar panel, the output power and voltage can be dropped gradually.

From table I, we conclude that the voltage and power levels are dropped gradually from the day I - day VII. As a result, the efficiency was not better, which is disadvantageous to the consumers.

From table II, we conclude that the voltage and power levels from day I - day VII are much better than table I, i.e., the efficiency of a solar panel with automation is better than the efficiency of a solar panel without using automation.

\subsection{Characteristics:}

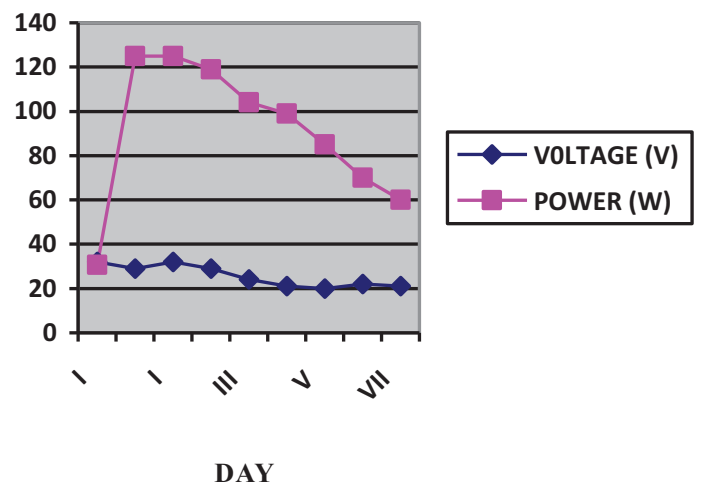

Figure27. P-V characteristics of solar panel without solar panel cleaner.

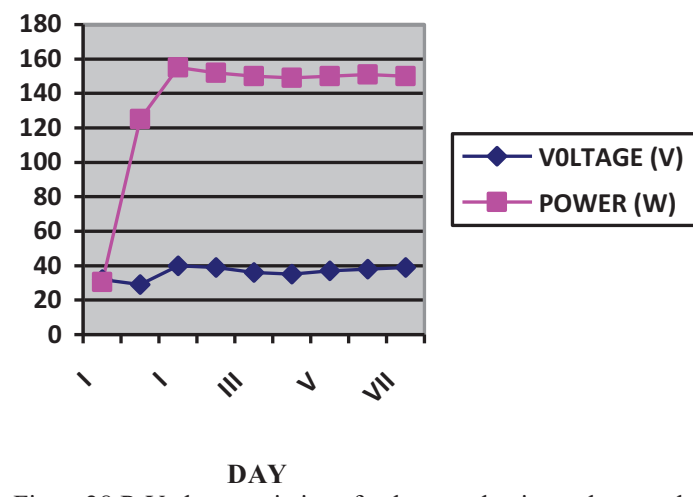

Figure28.P-V characteristics of solar panel using solar panel

Cleaner.

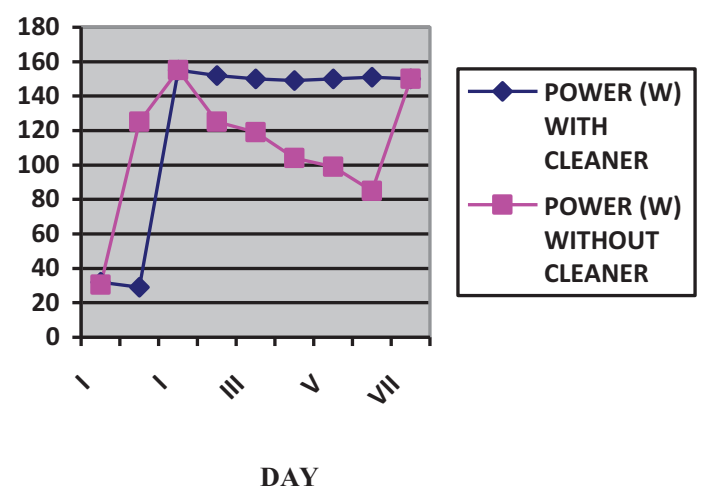

Figure 29. Comparing the power of solar panel, with and without using solar panel cleaner. 


\section{Conclusions}

In a solar panel, cleaner designing is a very important task, thereafter controlling mechanism. During the cleaning mechanism some observations were made:

- The linear actuator system working was very nice, so it achieves the desired system parameter.

- Using screw rod some unstable disturbances occur, therefore some changes are necessary for the screw mechanism.

- There is a chance of reducing the weight of the gantry. As a result, the thrust can be reduced on the panel.

- The scrubber should attach with the gantry; therefore, the cleaning process is much efficient, i.e., the sticky dust can be removed on the solar panel.

\section{FUtURE SCOPE}

Automatic solar panel cleaner requires the following modifications, which can be improved as follows:

- To clean 1 MW plant area of solar panels, in a short interval of time.

- To maintain the cleaning mechanism should be uniform.

- An automatic weather detector mechanism should be included in this solar panel cleaner.

- Weather forecasting data should include in this mechanism.

- A dust analyser should include in this mechanism.

\section{REFERENCES}

[1] R.E.P.N. for the $21^{\text {st }}$ Century, "Renewable 2012, global status report"., tech.rep.,

[2] J. Zorilla-Casanova, "Analysis of dust losses in Photovoltaic modules" of world renewable Energy Congress2011.Sweden, 8-13 May 2011.

[3] Katz.G. (2008, 27 April 2011)," Effect of dust on Solar panel". Available: www.gregorybkatz.com.

[4] Shaharin A. Suleiman, Haizatul," Energy efficiency of solar panel". Indian streams research journal ISSN 2230-7850.

[5] K.A. Moharram, M.S. Abd - Elhady, H.A. K and H. ElSheriff," Influence of cleaning using water and surfactants on performance of photovoltaic panels". Energy convers. Manage., vol.68, pp.266272,2013.

DOI: 10.1016/j.enconman.2013.01.022.

[6] Mohammad A. Bou-Rabee," Influence of Dirt Accumulation on performance of PV panels. "Available: http://docseurope.electrocomponents.com.

[7] El-Shobokshy MS, Hussein FM," degradation of PV performance due to dust deposition on to its surface." J Renew energy 1993. 